\title{
Fatigue Failure and Thermal Spalling Tests to Evaluate Dynamic Fatigue Fracture of $\mathrm{MgO}-\mathrm{C}$ Bricks
}

\author{
Yuta HINO and Yoshisato KIYOTA \\ Slag and Refractories Dept., Steel Research Laboratory, JFE Steel Corporation, Chiba, Japan. \\ (Received on July 5, 2011; accepted on August 3, 2011)
}

\begin{abstract}
The relationship between compressive stress and loading cycles in $\mathrm{MgO}-\mathrm{C}$ bricks with various carbon contents was investigated at room temperature and high temperature. The relationship between fatigue failure and thermal spalling was investigated by estimating a characteristic material constant, which represents the degree of sensitivity of crack growth, in terms of fracture mechanics.

The relationship between the ratio of compressive stress for compressive strength and loading cycles in $\mathrm{MgO}-\mathrm{C}$ bricks is not affected by the temperature of the atmosphere. At the same acting stress ratio, fatigue fracture life decreased as the carbon content in the $\mathrm{MgO}-\mathrm{C}$ bricks decreased. In the thermal spalling test, the number of heating cycles at which small cracks and large cracks were generated decreased as the carbon content decreased. In the fatigue failure test, the ratio of the dynamic elastic modulus to the initial elastic modulus decreased gradually. This ratio also showed a gradual decrease in the thermal spalling test as the number of heating cycles increased. A characteristic material constant was obtained and compared based on the results of a fracture mechanics discussion. The characteristic material constant obtained from the fatigue failure test was substantially the same as that obtained from the thermal spalling test. From this, a relationship in which crack growth behavior leading to fatigue failure is equivalent to that of thermal spalling in $\mathrm{MgO}-\mathrm{C}$ brick was recognized.
\end{abstract}

KEY WORDS: fatigue fracture; thermal spalling; MgO-C brick; stress; fracture mechanics.

\section{Introduction}

The refining processes used in ironmaking and steelmaking are often of a batch type, in which heat input and discharge occur cyclically. Taking the operation cycle of the converter as an example, the following process is conducted repeatedly: First, scrap is charged into the bottom of the converter, followed by charging of molten pig iron (hot metal). Next, refining operations for decarburization or dephosphorization are performed by blowing oxygen gas from a top blowing lance or bottom tuyere. When refining is complete, the molten steel is tapped into a ladle. In this process, the surface temperature of the wear refractory increases from charging of the hot metal to refining, and then decreases from tapping until charging of the hot metal for the next charge. The torpedo car used to transport hot metal and the steelmaking ladle are also affected by similar heat cycles.

When the refractories for ironmaking and steelmaking equipment are subjected to continuous cyclical inputs and discharges of heat, the thermal stress affecting the refractories also changes corresponding to these temperature changes. This causes cracks in the refractories and contributes to increased erosion or corrosion by the steelmaking slag and fracture by thermal spalling. These types of damage are not instantaneous, but are phenomena which develop progressively over a long time span.

This suggests that it is necessary to investigate the relationship between the continuous cyclical inputs and dis- charges of heat and fracture of refractories over an extended time, considering the duration of crack propagation in the refractory material before fracture.

Generally, the fundamental equation for thermal stress is expressed by a thermal expansion coefficient, $\alpha(1 / \mathrm{K})$, the elastic modulus, $E(\mathrm{~Pa})$, the difference of temperature, $\Delta T$ $(\mathrm{K})$, and Poisson's ratio, $v{ }^{1)}$ In the thermal stress equation, the factor which changes as the ambient temperature changes is the thermal expansion ratio, namely, $\alpha \cdot \Delta T$. In actual steelmaking equipment using refractories, it was considered that thermal stress changed as thermal expansion and shrinkage occurred periodically. Therefore, in conventional studies, the thermal expansion ratio and elastic modulus were regarded as the objects of discussion, and refractory performance was improved by controlling the elastic modulus and the coefficient of thermal expansion of the material. ${ }^{2,3)}$ When the thermal expansion ratio $\alpha \cdot \Delta T$ changes, changes in mechanical properties such as the modulus of rupture are conceivable. However, due to the focus on elasticity and thermal expansion properties, inadequate attention had been given to study of the extent to which the thermal stress generated by cyclic heat changes contributes to the modulus of rupture of refractory materials, and as a result, how many repetitions of thermal changes refractory materials can withstand before fracture.

In this study, the behavior of crack growth in refractory materials was considered separately from the thermal expansion ratio and elastic modulus by conducting a test in 
which periodical stress was loaded directly on the material, namely, a fatigue failure test, as a first step, and the fatigue life of refractories under periodical stress loading was evaluated. Many studies have investigated fatigue failure in the fields of ceramics and concrete technology ${ }^{4-11)}$ from the viewpoint of analysis of fracture behavior under periodical stress loading. However, there have been very few studies or reports in connection with refractory technology. ${ }^{12-15)}$

Based on the above, as the $\mathrm{MgO}-\mathrm{C}$ brick was the subject of the evaluation in this study, the fatigue failure of $\mathrm{MgO}-\mathrm{C}$ was investigated by applying periodical compressive loading to bricks. The relationship between fatigue failure and thermal spalling was also investigated by estimating the fatigue failure behavior of $\mathrm{MgO}-\mathrm{C}$ bricks with different carbon contents.

\section{Experimental Procedure}

\subsection{Fatigue Failure Test}

A schematic diagram of the experimental procedure is shown in Fig. 1, and the experimental conditions are summarized in Table 1. Three types of $\mathrm{MgO}-\mathrm{C}$ bricks, which contained $10 \%, 15 \%$ and $20 \%$ of graphite, respectively, were used as samples. In $\mathrm{MgO}-\mathrm{C}$ bricks, a phenol resin system organic material was used as a binder. When these bricks were heated under typical conditions used in steelmaking furnaces (atmosphere temperature: 1273-1923 K or more, $\mathrm{CO}$ rich gas atmosphere), volatilization of the binder occurred and the properties of the brick changed from those of the initial brick. In this study, the sample bricks were prepared by heat treatment at a temperature of 1623 $\mathrm{K}$ with a holding time of 3 hours in a coke-filled atmosphere to simulate the conditions inside an actual furnace and prevent carbon loss during heating. Compressive loads were applied periodically to the samples using a waveform with a 100 second cycle i.e., $0.01 \mathrm{~Hz}$, as shown in Fig. 2, at room

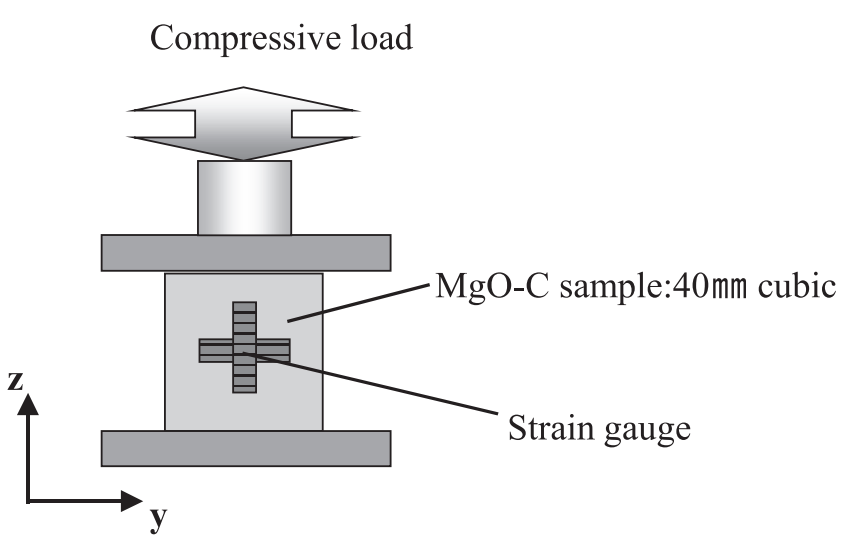

Fig. 1. Experimental apparatus for fatigue fracture test.

Table 1. Experimental conditions for fatigue failure test.

\begin{tabular}{|c|c|c|c|c|}
\hline \multicolumn{2}{|c|}{ Sample } & $\mathrm{MgO}-10 \% \mathrm{C}$ & $\mathrm{MgO}-15 \% \mathrm{C}$ & $\mathrm{MgO}-20 \% \mathrm{C}$ \\
\hline \multicolumn{2}{|l|}{ Sample size } & \multicolumn{3}{|c|}{$40 \mathrm{~mm}$ cubic } \\
\hline \multicolumn{2}{|c|}{ Atmosphere temperature } & \multicolumn{3}{|c|}{$298 \mathrm{~K}, 1273 \mathrm{~K}, 1473 \mathrm{~K}$} \\
\hline \multicolumn{2}{|c|}{ Loading frequency } & \multicolumn{3}{|c|}{$0.01 \mathrm{~Hz}$} \\
\hline \multirow{2}{*}{$\begin{array}{l}\text { Compressive } \\
\text { load }\end{array}$} & Upper limit & \multicolumn{3}{|c|}{$73 \%-100 \%$ of $\sigma_{\mathrm{C}}$} \\
\hline & Lower limit & \multicolumn{3}{|c|}{$10 \%$ of $\sigma_{\mathrm{C}}$} \\
\hline
\end{tabular}

temperature or a high temperature over $1273 \mathrm{~K}$ in a furnace. The lower limit of compressive loading was a constant value of $10 \%$ of compressive strength $\left(\sigma_{\mathrm{C}}\right)$, which has the same meaning as the modulus of rupture under compressive stress, while the upper limit of loading was changed from $73 \%$ to $100 \%$ of compressive strength $\left(\sigma_{\mathrm{C}}\right)$. The atmosphere temperature was room temperature, $1273 \mathrm{~K}$ or $1473 \mathrm{~K}$. The fatigue failure tests were mainly performed at room temperature, but tests were also done at high temperatures of 1273 $\mathrm{K}$ and $1473 \mathrm{~K}$ in the case of the $\mathrm{MgO}-20 \% \mathrm{C}$ brick.

Before conducting the fatigue failure test, a static compressive loading test of the bricks was performed and the compressive strength was measured in various bricks and under various conditions. Figure 3 shows the relationship between the compressive strength and atmosphere temperature in each brick. Table 2 shows the average values of compressive strength under each condition. The upper limit of the loading value in the fatigue failure test was determined

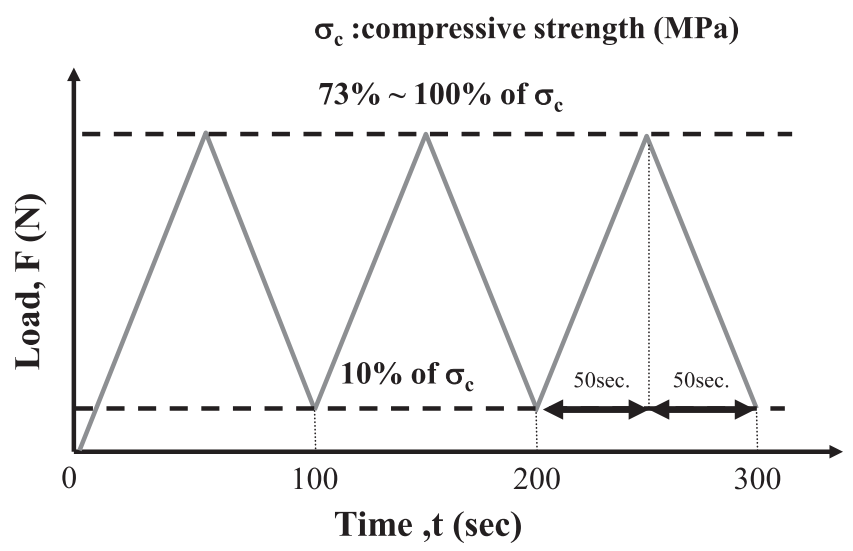

Fig. 2. Loading pattern in this work.

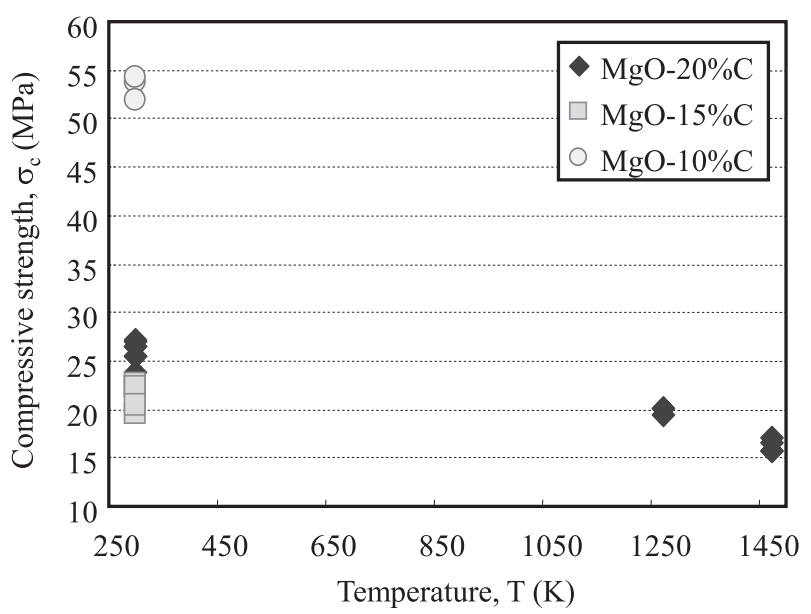

Fig. 3. Relationship between compressive strength and atmosphere temperature used in this study.

Table 2. Average value of compressive strength of $\mathrm{MgO}-\mathrm{C}$ brick.

\begin{tabular}{l|r|c|c|c}
\hline \multicolumn{2}{c|}{ Sample } & $\mathrm{MgO}-10 \% \mathrm{C}$ & $\mathrm{MgO}-15 \% \mathrm{C}$ & $\mathrm{MgO}-20 \% \mathrm{C}$ \\
\hline \multirow{2}{*}{$\begin{array}{l}\text { Compressive } \\
\text { strength, } \sigma_{\mathrm{C}} \\
(\mathrm{MPa})\end{array}$} & $298 \mathrm{~K}$ & 53.3 & 21.5 & 25.4 \\
\cline { 2 - 5 } & $1273 \mathrm{~K}$ & & & 18.6 \\
\cline { 2 - 5 } & $1473 \mathrm{~K}$ & & & 17.0 \\
\hline
\end{tabular}


by using the mean value shown in Table 2, and the fatigue failure test was performed.

Furthermore, the dynamic elastic modulus of the sample at each number of repetitions was measured in order to investigate the changes in the ratio of increase of cracks and pores in the brick when cyclic compressive stress was applied to the sample in the fatigue failure test. Here, the dynamic elastic modulus represents the modulus of elasticity in an adiabatic process. This property can be calculated from Eq. (1) by deriving the value of the sonic velocity propagated in the material from answering time measurement. ${ }^{16}$ )

$$
E=v^{2} \cdot \rho=\left(\frac{X}{t_{S}}\right)^{2} \cdot \rho
$$

where, $X(\mathrm{~m})$ is the length of the sample, $t_{\mathrm{s}}(\mathrm{s})$ is answering time and $\rho\left(\mathrm{kg} / \mathrm{m}^{3}\right)$ is bulk density.

\subsection{Thermal Spalling Test}

Figure 4 and Table 3 show the experimental apparatus and experimental conditions for the thermal spalling test of the $\mathrm{MgO}-\mathrm{C}$ bricks. Sample $\mathrm{MgO}-\mathrm{C}$ bricks were inserted into the furnace, which had been heated to $1673 \mathrm{~K}$, heated for 15 minutes, and then removed and quenched in water. This operation was repeated from one to ten times with each sample. The samples used in this test were of the same kind as those used in the fatigue failure test. In the thermal spalling test, the dynamic elastic modulus of the sample at each number of repetitions was measured in order to investigate the changes in the ratio of increase of cracks and pores in the brick when cyclical heating and quenching were applied to the sample. The dynamic elastic modulus can be calculated from Eq. (1) by deriving the value of the sonic velocity propagated in the material from answering time measure-

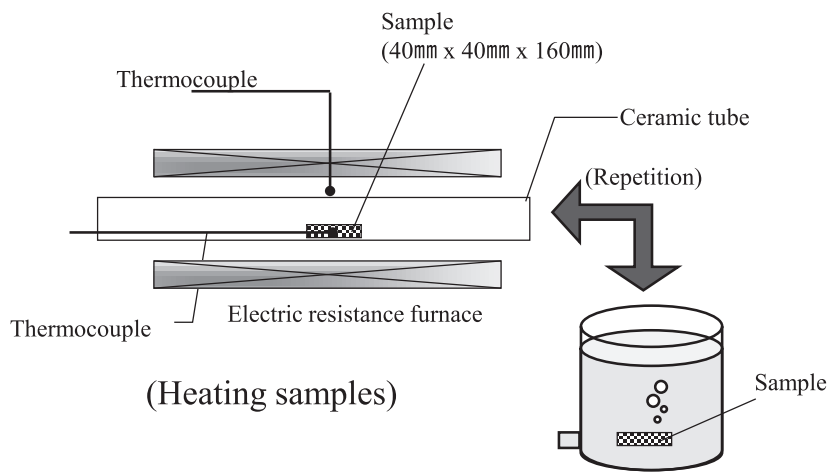

(Quenching in the water)

Fig. 4. Experimental apparatus for thermal spalling of $\mathrm{MgO}-\mathrm{C}$ brick.

Table 3. Experimental conditions for thermal spalling test.

\begin{tabular}{|c|c|c|c|}
\hline Sample & $\mathrm{MgO}-10 \% \mathrm{C}$ & $\mathrm{MgO}-15 \% \mathrm{C}$ & $\mathrm{MgO}-20 \% \mathrm{C}$ \\
\hline Sample size & \multicolumn{3}{|c|}{$40 \mathrm{~mm} \times 40 \mathrm{~mm} \times 160 \mathrm{~mm}$} \\
\hline $\begin{array}{l}\text { Atmosphere temperature } \\
\text { of heating }\end{array}$ & \multicolumn{3}{|c|}{$1673 \mathrm{~K}$} \\
\hline Holding time & \multicolumn{3}{|c|}{$15 \mathrm{~min}$} \\
\hline Quenching method & \multicolumn{3}{|c|}{ Water quenching for $3 \mathrm{~min}$} \\
\hline Frequency of repetition & \multicolumn{3}{|c|}{10} \\
\hline
\end{tabular}

ment in the same manner as in the fatigue failure test.

\section{Experimental Results}

\subsection{Fatigue Failure Test}

Figure 5 shows the relationship between compressive stress and the number of repetitions, that is, the $\mathrm{S}-\mathrm{N}$ curve, for the $\mathrm{MgO}-20 \% \mathrm{C}$ brick in experiments at room temperature. Here, the short dashed line in Fig. 5 shows the estimated range where the fatigue fracture could occur. This estimation was obtained by the following examinations. Treatment of Weibull statistics analysis employing the data plotted in Fig. 5 leads to the probable range of approximately $\pm 10 \%$ against the mean value considering that the possible stress range to have fracture is estimated as $99 \%$ in domination level. This was caused by the deviation of the original $\mathrm{MgO}-\mathrm{C}$ brick material. The possible stress range to be fractured as above estimated is well consistent with a presumed range derived by the inclination of the regression line for the plot in Fig. 5. This fact safely indicates that every plot in the $\mathrm{S}-\mathrm{N}$ curve shown in Fig. 5 positions in the probable stress range to have fracture given by the dashed thresholds. The evaluation of the experimental results is discussed in the following.

Figure 6 shows the relationship between compressive stress and the number of repetitions for the $\mathrm{MgO}-20 \% \mathrm{C}$

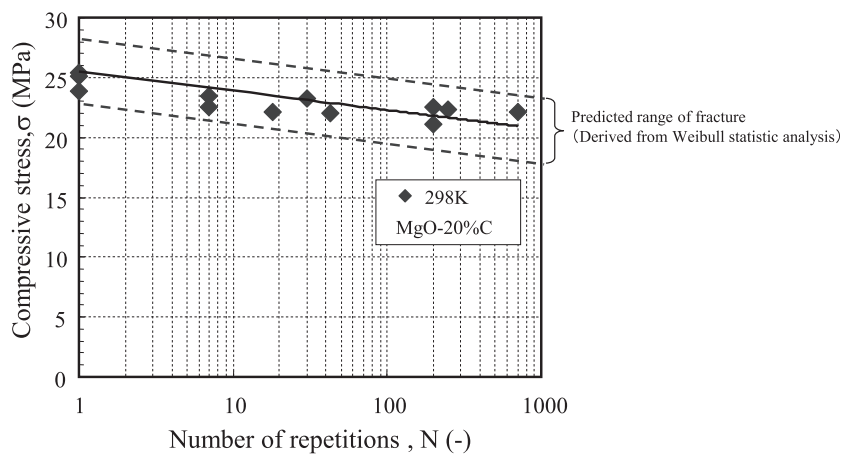

Fig. 5. Relationship between compressive stress and number of repetitions of loading for $\mathrm{MgO}-20 \% \mathrm{C}$ brick at room temperature.

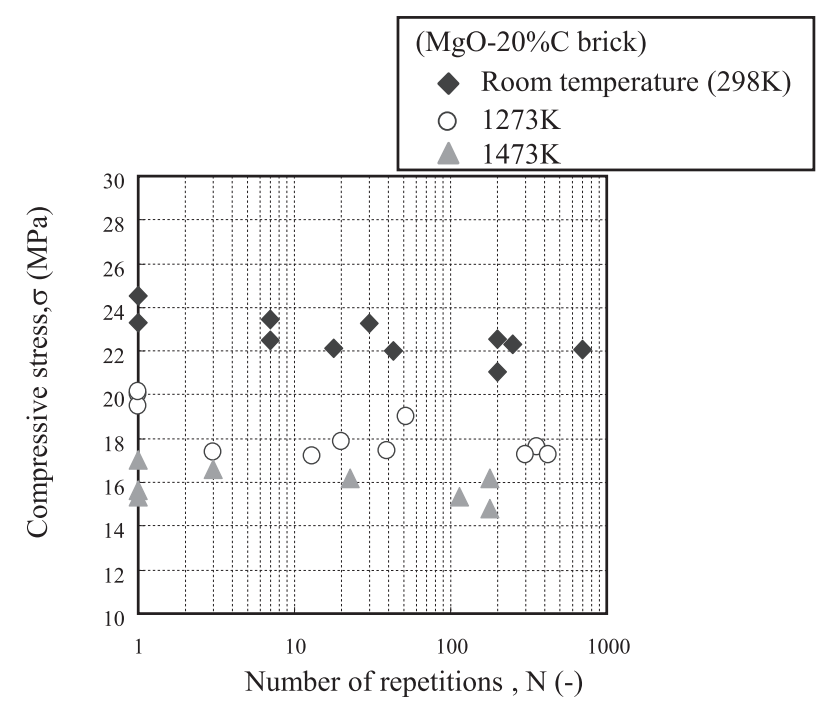

Fig. 6. Relationship between compressive stress and number of repetitions of loading for $\mathrm{MgO}-\mathrm{C}$ brick ( $\mathrm{S}-\mathrm{N}$ curve). 
brick in experiments at room temperature, $1273 \mathrm{~K}$ and 1473 K, respectively. Figure 7 shows the results when the compressive crushing strength was assumed to be $100 \%$ and the load stress value was converted to the acting stress ratio (i.e., compressive stress ratio). It is noted that $\mathrm{S}-\mathrm{N}$ diagram has been made by accounting for the relationship between the compressive strength and the dynamic modulus of elasticity along with estimating the compressive strength of each sample to minimize the scattering. The experimental results were compared for each condition considering the above-mentioned deviation. In Fig. 7, the number of repetitions to failure increased as the acting stress ratio decreased in the case of $\mathrm{MgO}-\mathrm{C}$ brick. This behavior is similar to that in ceramics, concrete, and metallic materials. The relationships of fatigue fracture life at the same acting stress ratio were almost the same at room temperature, $1273 \mathrm{~K}$ and
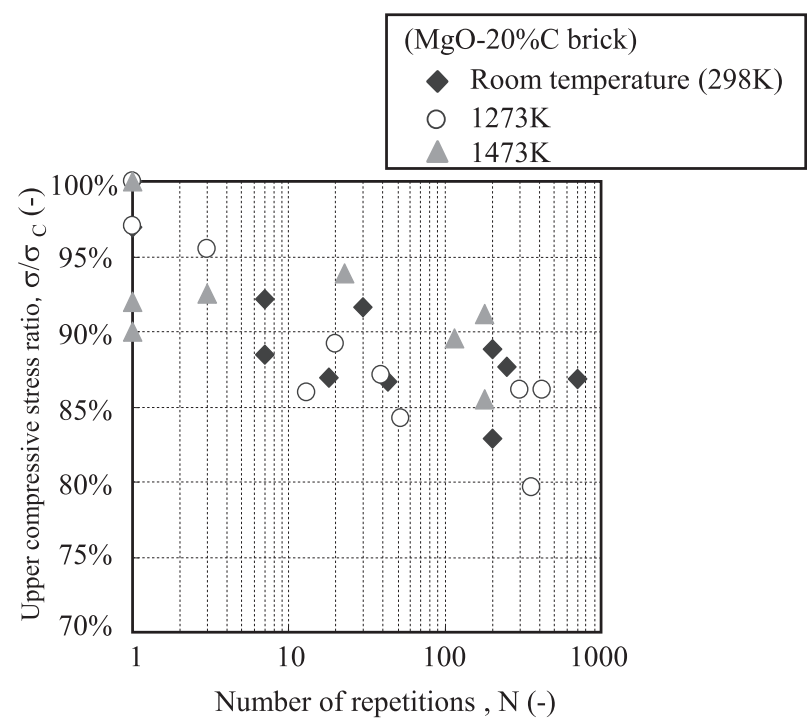

Fig. 7. Relationship between upper compressive stress ratio and number of repetitions in $\mathrm{MgO}-20 \% \mathrm{C}$ brick.

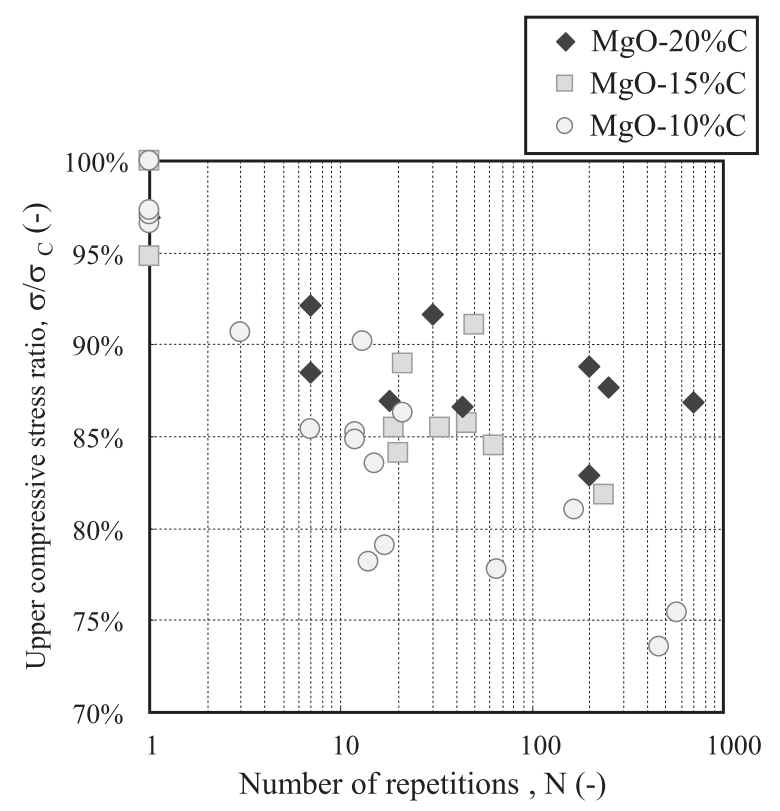

Fig. 8. Relationship between compressive stress ratio and number of repetitions in $\mathrm{MgO}-10 \% \mathrm{C}, \mathrm{MgO}-15 \% \mathrm{C}$ and $\mathrm{MgO}-$ $20 \% \mathrm{C}$ bricks.
$1473 \mathrm{~K}$. In other words, the fatigue fracture behavior of $\mathrm{MgO}-\mathrm{C}$ brick did not display temperature dependence.

Figure 8 shows the relationship between the compressive stress ratio and number of repetitions to failure in the $\mathrm{MgO}$ $\mathrm{C}$ bricks which contained $10 \%, 15 \%$ and $20 \% \mathrm{C}$ in an experiment at room temperature. Comparing these $\mathrm{MgO}-\mathrm{C}$ bricks, the fatigue fracture life at the same acting stress ratio decreased as the carbon content in the $\mathrm{MgO}-\mathrm{C}$ brick decreased.

The changes of strains in the horizontal and vertical directions when compressive stress was applied periodically are shown in Figs. 9 and 10, where positive values indicate tension (tensile strain) and negative values show compression (compressive strain). It was assumed that the depth direction (X direction) was equivalent to the horizontal direction (Y direction). In this study, tensile strain was generated in the horizontal direction and compressive strain was generated in the vertical direction as a result of Poisson's effect. The maximum and minimum values were extracted from these figures and arranged in terms of the number of repetitions of loading. Figures 11 and 12 show the relationship between the amount of maximum strain in the horizontal and vertical directions and the number of repetitions in $\mathrm{MgO}-15 \% \mathrm{C}$ and

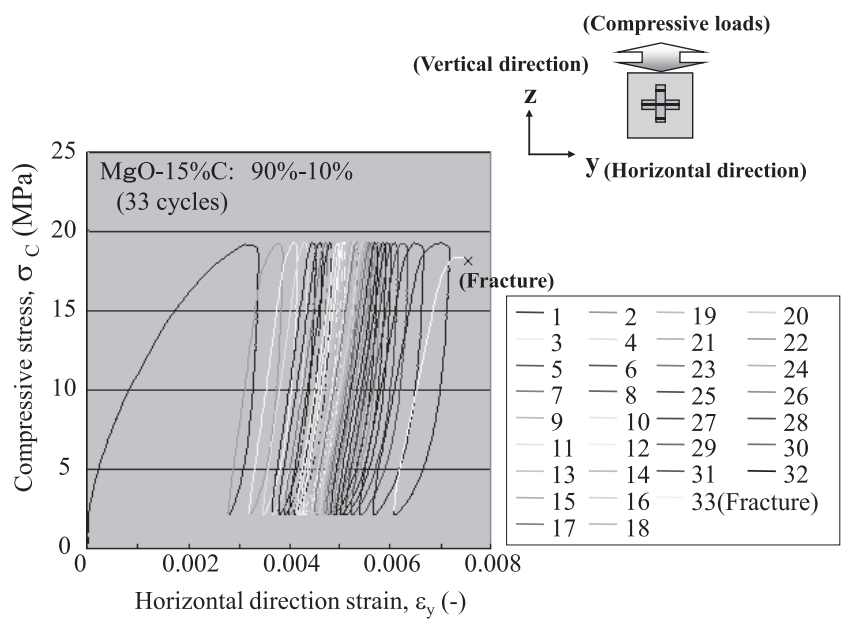

Fig. 9. Changes of strain in horizontal direction under periodic compressive loading.

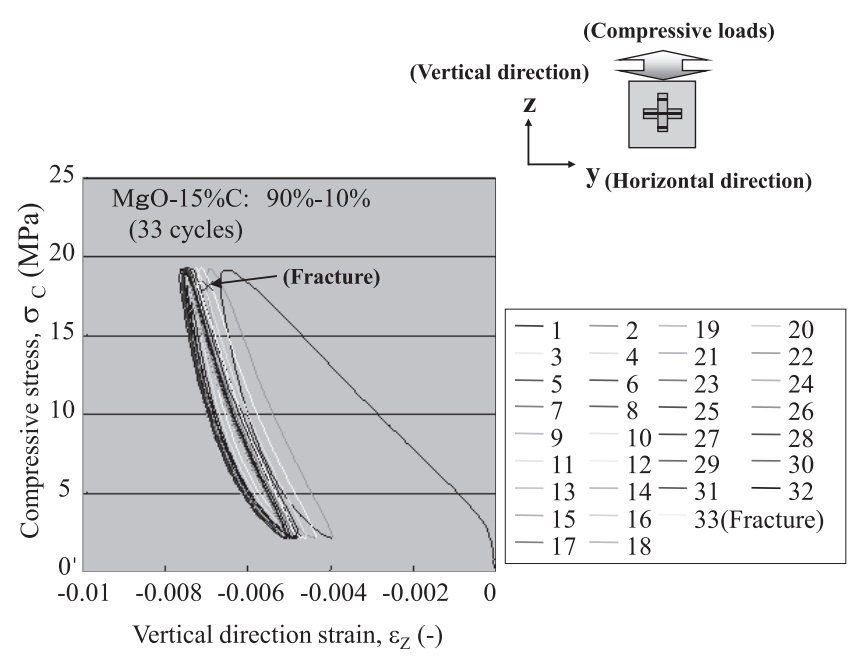

Fig. 10. Changes of strain in vertical direction under periodic compressive loading. 
$\mathrm{MgO}-20 \% \mathrm{C}$, respectively. Focusing on the horizontal strain, the value of strain increased gradually in the first stage of repetition in both samples. The amount of strain in

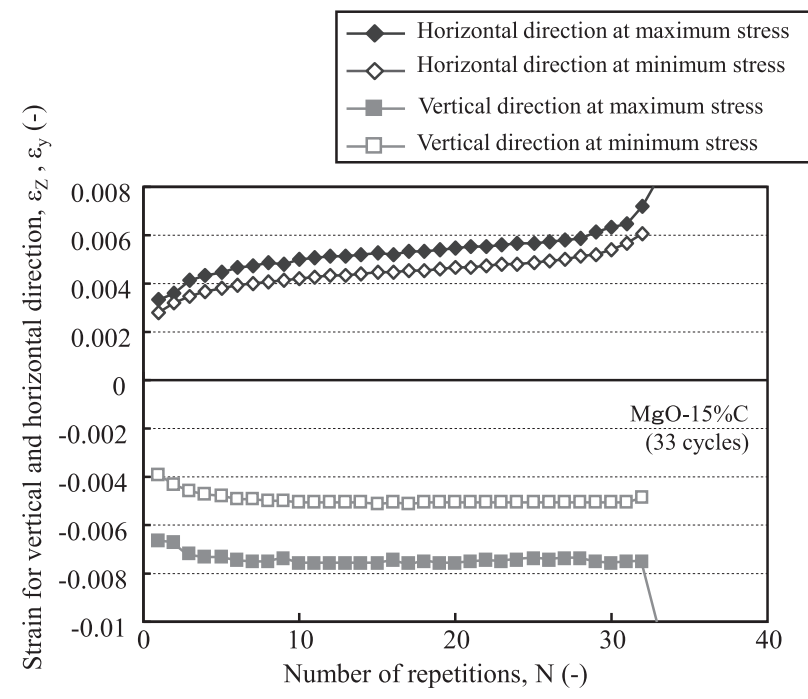

Fig. 11. Relationship between vertical and horizontal strain values at maximum and minimum stress and number of repetitions in $\mathrm{MgO}-15 \% \mathrm{C}$ brick.

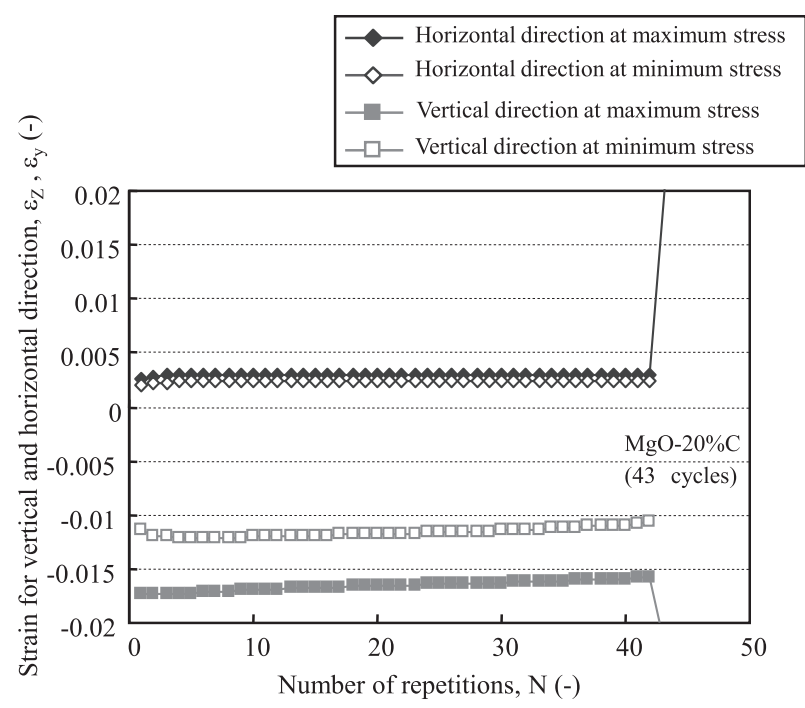

Fig. 12. Relationship between vertical and horizontal strain values at maximum and minimum stress and number of repetitions in $\mathrm{MgO}-20 \% \mathrm{C}$ brick. the middle stage of repetition increased gradually in the $\mathrm{MgO}-15 \% \mathrm{C}$ brick, but was almost constant in the $\mathrm{MgO}-$ $20 \%$ C. Moreover, the strain rate per unit loading cycle increased rapidly immediately before fracture in the $\mathrm{MgO}$ $20 \% \mathrm{C}$ brick, while the strain rate increased gradually a few cycles before fracture in the $\mathrm{MgO}-15 \% \mathrm{C}$ brick. These strain behaviors will be discussed in detail later in this paper. In contrast, vertical strain decreased gradually in the first stage, became substantially constant in the middle region, and then decreased just before fracture. The values of Poisson's ratio were derived from the values of strain in the horizontal and vertical directions. Table 4 shows the Poisson's ratios obtained with $\mathrm{MgO}-\mathrm{C}$ bricks of each carbon content.

\subsection{Thermal Spalling Test}

Figure 13 shows photographs of samples after three, five, seven heating and quenching cycles for the $\mathrm{MgO}-15 \% \mathrm{C}$ brick. (It may be noted that the surface of the sample shows slight oxidation, as the air-tightness of the furnace was not perfect. However, the effect of surface oxidation of the samples on the thermal spalling behavior of the brick was very small, and was considered negligible because the oxidation area was limited to the surface and the degree of oxidation was very slight.) Comparatively small cracks, which were under $20 \mathrm{~mm}$ in size, were generated partially on the sample after three heating and quenching cycles (this type of crack was defined as "small crack"). After five heating and quenching cycles, small cracks under $20 \mathrm{~mm}$ were generated on the total surface of the sample, and after seven heating and quenching cycles, more comparatively large cracks, which were larger than $20 \mathrm{~mm}$ in size, were generated and spalling also occurred (this type of crack was defined as "large crack"). These small and large cracks were observed in all samples.

Figure 14 shows a comparison of the number of heating cycles at which small cracks were generated on the partial or total surface of the sample and large cracks occurred with $\mathrm{MgO}-10 \% \mathrm{C}, \mathrm{MgO}-15 \% \mathrm{C}$ and $\mathrm{MgO}-20 \% \mathrm{C}$ brick samples. The number of heating cycles for generation of small cracks and large cracks decreased as the carbon content in the bricks decreased.

Table 4. List of Poisson's ratios for sample brick materials.

\begin{tabular}{c|c|c|c}
\hline Sample & $\mathrm{MgO}-10 \% \mathrm{C}$ & $\mathrm{MgO}-15 \% \mathrm{C}$ & $\mathrm{MgO}-20 \% \mathrm{C}$ \\
\hline Poisson's ratio,n & 0.42 & 0.38 & 0.35 \\
\hline
\end{tabular}

$\mathrm{MgO}-15 \% \mathrm{C}$

3 cycles

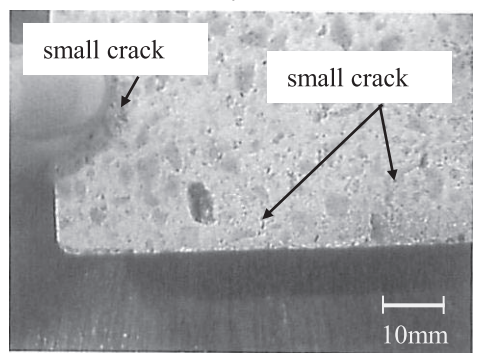

5 cycles

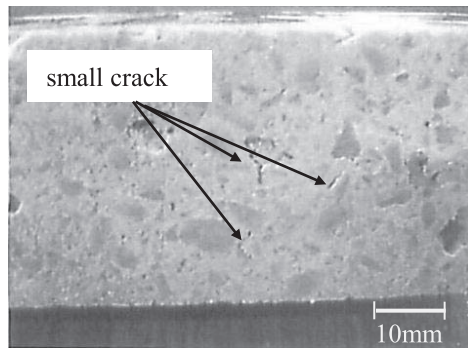

7 cycles

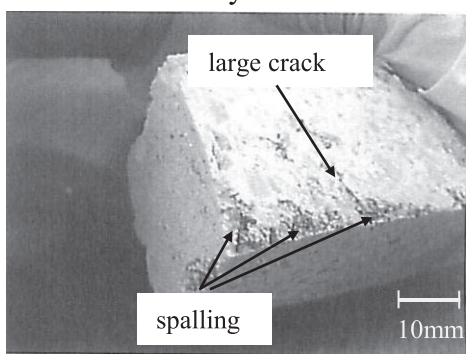

Fig. 13. Photographs of samples after three, five, seven heating and quenching cycles ( $\mathrm{MgO}-15 \% \mathrm{C})$. 


\subsection{Behavior of Dynamic Elastic Modulus}

It was considered that the fracture phenomenon occurred as a result of increase in the crack ratio or progress of cracks, which were initially present in the material or were generated by loading, when the brick was subjected to cyclic compressive stress or thermal spalling. In this study, changes in the dynamic elastic modulus were investigated as a method of evaluating the increase or progress of cracks in the $\mathrm{MgO}-\mathrm{C}$ bricks in the fatigue failure test and thermal spalling test. When cracks or pores were present in the material, the dynamic elastic modulus was inclined to decrease. Due to this behavior, the higher value of the decreasing ratio of the dynamic elastic modulus compared with initial value could lead to an increase in the crack ratio or progress of cracks in the material. Therefore, the changes of the dynamic elastic modulus in the fatigue failure test and thermal spalling test were evaluated at room temperature.

Figure 15 shows the change in the dynamic elastic mod-

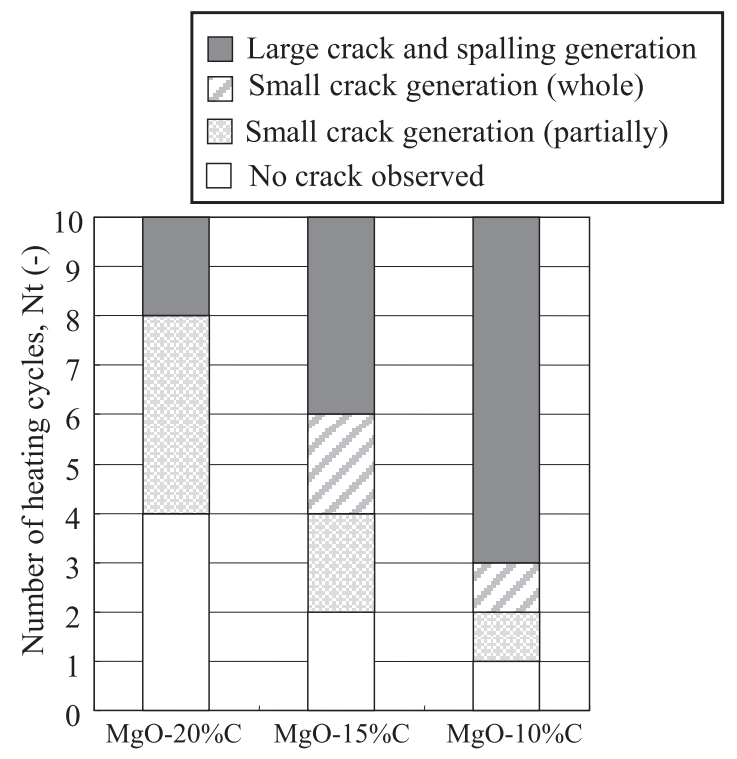

Fig. 14. Result of spalling test of $\mathrm{MgO}-\mathrm{C}$ brick.

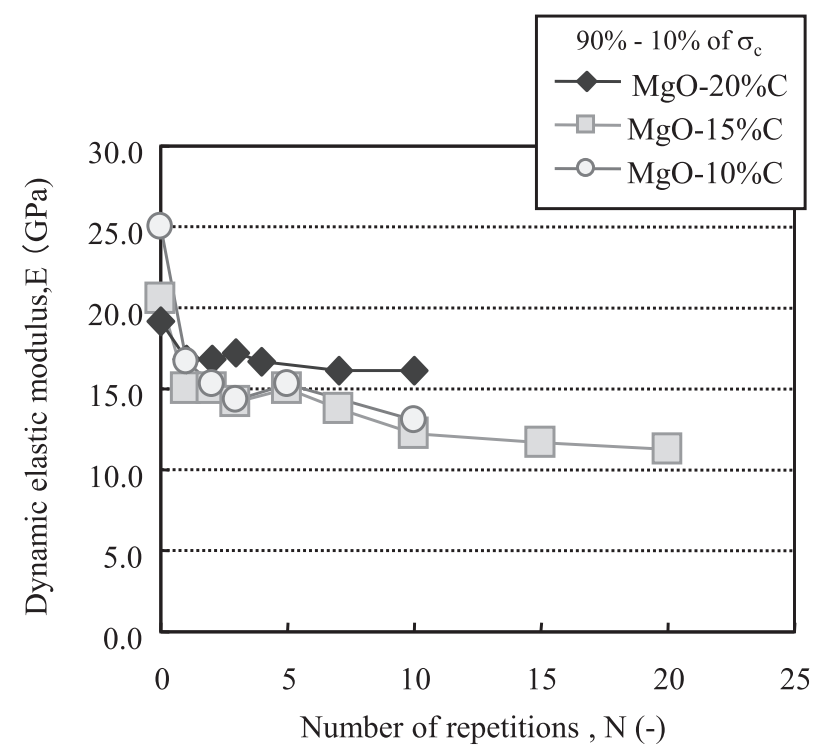

Fig. 15. Changes of dynamic elastic modulus in $\mathrm{MgO}-10 \% \mathrm{C}$, $\mathrm{MgO}-15 \% \mathrm{C}$ and $\mathrm{MgO}-20 \% \mathrm{C}$ bricks. ulus in the $\mathrm{MgO}-10 \% \mathrm{C}, \mathrm{MgO}-15 \% \mathrm{C}$ and $\mathrm{MgO}-20 \% \mathrm{C}$ brick samples, respectively, when cyclic loads were applied. Fig. 16 shows the changes of the ratio of the dynamic elastic modulus to the initial elastic modulus modified by the results of Fig. 15. In all cases, the ratio of the dynamic elastic modulus to the initial elastic modulus decreased greatly in the first cycle, and continued to decrease gradually thereafter. The rate of decrease in the dynamic elastic modulus became larger as the carbon content in the brick decreased.

Figure 17 shows the change in the dynamic elastic modulus in $\mathrm{MgO}-10 \% \mathrm{C}, \mathrm{MgO}-15 \% \mathrm{C}$ and $\mathrm{MgO}-20 \% \mathrm{C}$ brick samples, respectively, when cyclical heating and quenching were applied to the samples in the thermal spalling test. As the number of heating and quenching cycles increased, the ratio of the dynamic elastic modulus to the initial elastic modulus decreased gradually. As in the fatigue failure test, the rate of decrease of the dynamic elastic modulus became

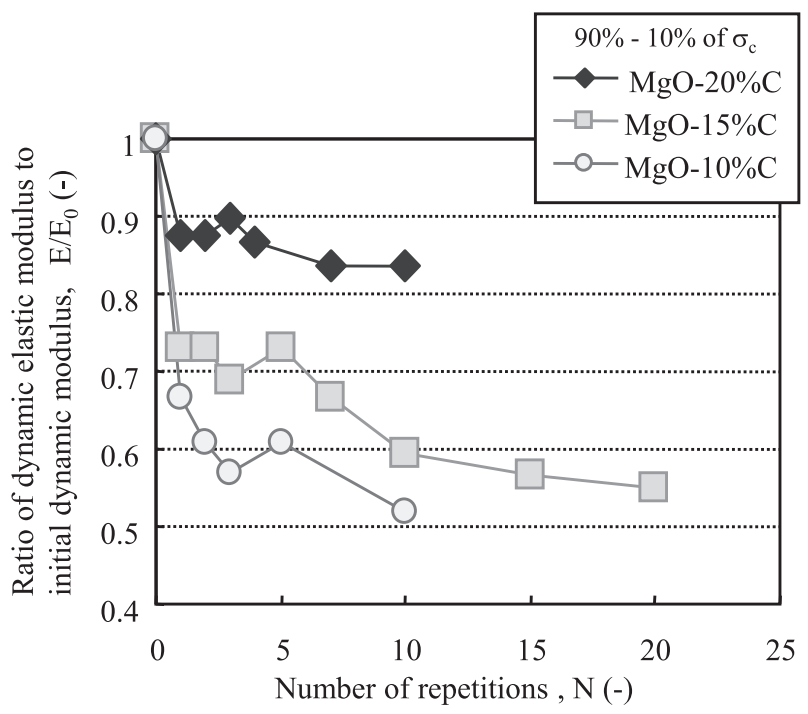

Fig. 16. Changes of ratio of dynamic elastic modulus to initial elastic modulus modified by results of Fig. 15.

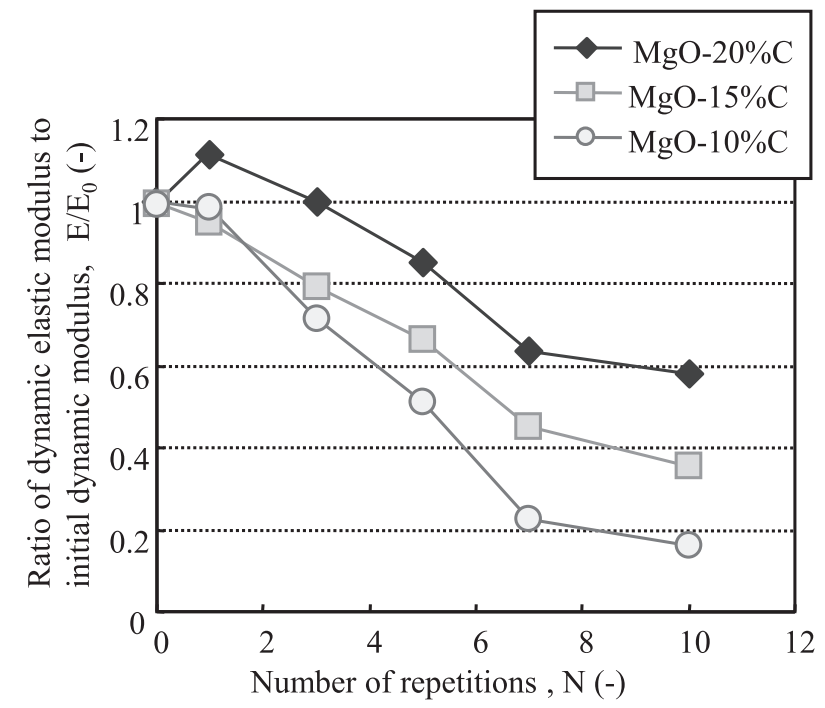

Fig. 17. Changes of dynamic elastic modulus in $\mathrm{MgO}-10 \% \mathrm{C}$, $\mathrm{MgO}-15 \% \mathrm{C}$ and $\mathrm{MgO}-20 \% \mathrm{C}$ bricks under cyclical heating and quenching of brick samples in thermal spalling test. 
larger as the carbon content in the bricks decreased.

From Fig. 16, it was predicted that many small cracks in the brick would be generated in the first loading cycle and the number of cracks would increase or the crack growth rate would increase thereafter, corresponding to the behavior of the ratio of the dynamic elastic modulus to the initial elastic modulus. When the behavior of the dynamic elastic modulus at thermal spalling was compared with that in the fatigue failure test, the tendency of decreasing dynamic elastic modulus depending on differences in carbon content in the thermal spalling test roughly corresponded to that in the fatigue failure test, even though comparatively large decreases in the elastic modulus were not observed in the thermal spalling test.

Therefore, as mentioned previously, it is considered that the progress or amount of generation of cracks increased in the bricks as a result of an increase in the number of heating and cooling cycles in the thermal spalling test, as increased crack generation in the material originates in the decrease of the dynamic modulus of elasticity. ${ }^{17-19)}$

From the results described above, a certain kind of similarity was confirmed between the fracture behaviors in fatigue failure and thermal spalling.

\section{Discussion}

\subsection{Fracture Mechanics Consideration}

In the previous section, a certain kind of similarity was confirmed between the fracture behaviors in fatigue failure and thermal spalling in terms of the decreasing behavior of the dynamic elastic modulus. Therefore, the fatigue fracture behavior of $\mathrm{MgO}-\mathrm{C}$ bricks was examined using fracture dynamics. ${ }^{19-21)}$ When the samples were observed after fatigue fracture, cracks had mainly progressed in the direction perpendicular to the loading phase, and horizontal strain increased slightly in the middle region of the fatigue failure test, as shown in Fig. 11. From these results, the fracture mode of these materials was regarded as mode I, which corresponds to tensile fracture based on Irwin's linear elastics theory. ${ }^{22}$ It was assumed that a crack which exists in the material will progress gradually in a stable manner under cyclical compressive load, and Paris's law can be applied to the crack progress behavior. The rate of crack growth can be expressed by Eq. (2). ${ }^{21}$

$$
\frac{d a}{d N}=C \cdot\left(\frac{\Delta K}{K_{1 C}}\right)^{n}
$$

where, $a$ is crack length, $N$ is number of cycles, $K_{l C}$ is fracture toughness, $C$ and $n$ are characteristic constants dependent on materials, and $\Delta K$ is the difference of stress intensity factor expressed by Eq. (3).

$$
\Delta K=K_{\max }-K_{\min }
$$

where, $K_{\max }$ and $K_{\min }$ are expressed as shown in Eq. (4) using a geometrical factor, $Y$, which was determined from the crack length and dimensions of the material, and the maximum and minimum applied stress, $\sigma_{\max }$ and $\sigma_{\min }$.

$$
K_{\max }=Y \sigma_{\max } \sqrt{\pi \cdot a} \quad K_{\min }=Y \sigma_{\min } \sqrt{\pi \cdot a}
$$

Equation (5) was obtained by substituting Eq. (4) for Eq. (3). Further, when Eq. (5) was substituted for Eq. (2) and the result of substitution was integrated, Eq. (6) was obtained.

$$
N=\int_{a_{0}}^{a_{C}} \frac{K_{1 C}^{n}}{C \cdot \Delta K^{n}} d a=\frac{2 K=Y \Delta \sigma \sqrt{\pi \cdot a}}{C \cdot Y^{n} \cdot \Delta \sigma^{n} \cdot \pi^{\frac{n}{2}} \cdot(n-2)}\left[a_{0}^{-\frac{n-2}{2}}-a_{C}^{-\frac{n-2}{2}}\right]
$$

where, $a_{0}$ means the initial length of a crack and $a_{C}$ means the length of the crack before fracture, respectively.

Finally, Eq. (7) was obtained by taking the logarithm of both sides of Eq. (6).

$$
\log \Delta \sigma=-\frac{1}{n} \log N+\frac{1}{n} \log \left[\frac{2 K_{1 C}^{n}}{C \cdot Y^{n} \cdot \pi^{\frac{n}{2}} \cdot(n-2)}\left[a^{-\frac{n-2}{2}}-a_{C}^{-\frac{n-2}{2}}\right]\right]
$$

When the results of the fatigue failure test shown in Figs. 6 to 8 , that is to say, the difference of the maximum and minimum stress, $\Delta \sigma$, and the number of cycles to fracture, $N$, were substituted for Eq. (7), and a linear relationship between $\log \Delta \sigma$ and $\log N$ was assumed, the numerical constant $n$ could be obtained. Here, $\Delta \sigma$ was given as a difference between $100 \%$ and $10 \%$ of the fracture stress value at every plot of $N=1$. Because this value was determined by the conditions of the material, atmosphere temperature, and experimental conditions, the index $n$ was compared and discussed for each condition in this study.

As an example of adjustment of the results, the relationships between $\Delta \sigma$ and $N$ in $\mathrm{MgO}-10 \% \mathrm{C}, \mathrm{MgO}-15 \% \mathrm{C}$ and $\mathrm{MgO}-20 \% \mathrm{C}$, respectively, are shown in Fig. 18. Since a linear relationship can be considered to exist between $\Delta \sigma$ and $N$ under all conditions, linear regression was done by the minimum mean square method, and the index $n$ was obtained from the inclination of the regression line under each condition. A list of the values of the index $n$ obtained from the results of the fatigue failure test is shown in Table 5. With the $\mathrm{MgO}-\mathrm{C}$ bricks used in the fatigue failure test in this study, the value of $n$ was smaller in the bricks with lower carbon contents. Moreover, no difference was seen in the

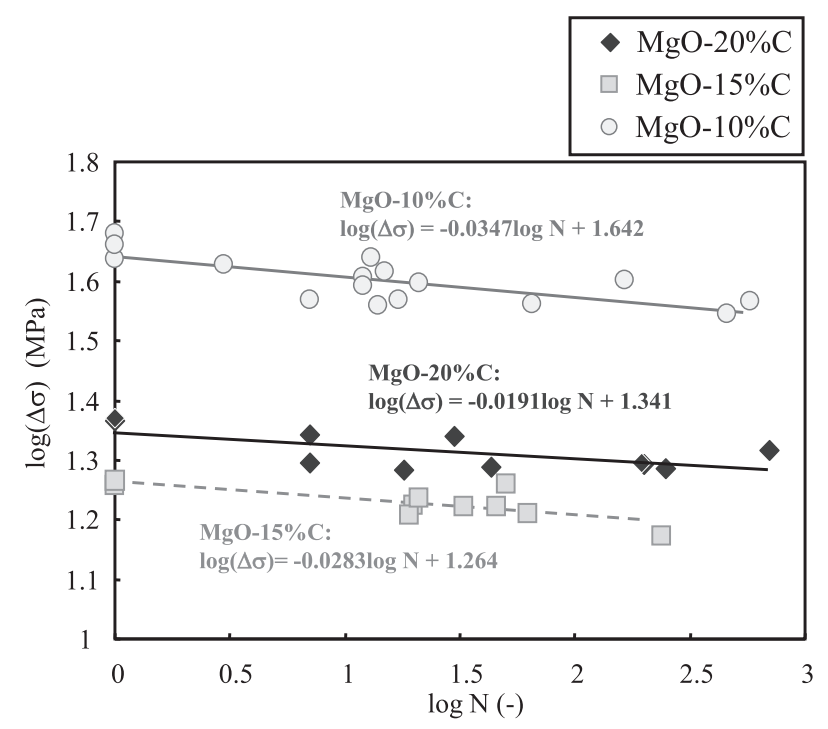

Fig. 18. Relationship between $\Delta \sigma$ and $N$ in $\mathrm{MgO}-\mathrm{C}$ bricks. 
Table 5. Values of material constant (numerical index ) $n$.

\begin{tabular}{cccc}
\hline Refractories & Temperature & Carbon content & $n$ \\
\hline $\mathrm{MgO}-10 \% \mathrm{C}$ & $298 \mathrm{~K}$ & $10 \%$ & 29.8 \\
$\mathrm{MgO}-15 \% \mathrm{C}$ & $298 \mathrm{~K}$ & $15 \%$ & 35.3 \\
$\mathrm{MgO}-20 \% \mathrm{C}$ & $298 \mathrm{~K}$ & $20 \%$ & 52.4 \\
$\mathrm{MgO}-20 \% \mathrm{C}$ & $1273 \mathrm{~K}$ & $20 \%$ & 52.9 \\
$\mathrm{MgO}-20 \% \mathrm{C}$ & $1473 \mathrm{~K}$ & $20 \%$ & 47.8 \\
\hline
\end{tabular}

value of $n$ at low temperature and high temperature in $\mathrm{MgO}-\mathrm{C}$ bricks with the same carbon content $(\mathrm{MgO}-20 \% \mathrm{C})$, the values being substantially equal under these two conditions.

\subsection{Examination of Relationship of Fatigue Fracture Behavior and Spalling}

The relationship of fatigue fracture behavior and spalling was examined based on the results presented in the above section. If Paris's law is assumed to be applicable to the rate of growth of a crack under repeated thermal shock, in other words, thermal fatigue, in the same manner as with mechanical fatigue, this relationship can be expressed by Eq. (8). ${ }^{1,2,23)}$

$$
\frac{d a}{d N}=C^{\prime} \cdot K^{\prime^{\prime \prime}} \cdot \exp \left(-\frac{Q}{R T}\right)
$$

where, $C^{\prime}$ and $n^{\prime}$ are numerical constants similar to those in Eq. (2), $K^{\prime}$ is the stress intensity factor, $Q$ is the apparent activation energy for crack growth, $R$ is the gas constant, and $T$ is the absolute temperature.

The stress intensity factor was expressed by Eq. (9) similarly to Eq. (4).

$$
K^{\prime}=Y \sigma \sqrt{\pi \cdot a}
$$

Equation (10) was obtained by integrating Eq. (8) and assuming approximately that the crack length at fracture was much larger than that in the initial condition.

$$
\begin{aligned}
N_{t} & =\int_{a_{0}}^{a_{c}} \frac{d a}{C^{\prime} \cdot K^{n^{\prime}} \exp \left(-\frac{Q}{R T}\right)} \\
& =\frac{2}{C^{\prime} \cdot Y^{n^{\prime}} \cdot \pi^{\frac{n^{\prime}}{2}} \cdot \sigma^{n^{\prime}} \cdot\left(n^{\prime}-2\right)} a^{-\frac{n^{\prime}-2}{2}} \exp \left(\frac{Q}{R T}\right)
\end{aligned}
$$

Because the refractories were quenched in a cascading water pool in the spalling test, the quenching condition could be assumed to be forced cooling by heat convection. On this assumption, the maximum stress generation could be calculated by Eq. (11), as proposed by Jeager et al. ${ }^{24)}$

$$
\frac{1}{\sigma}=\frac{1-v}{\alpha \cdot E \Delta T}\left(1.45+\frac{4.95}{\beta}\right)
$$

where, $\beta$ is a non-dimensional number called the bio number and is expressed by Eq. (12) using thermal conductivity $k$ $(\mathrm{J} / \mathrm{s} / \mathrm{m} / \mathrm{K})$, the heat transfer coefficient $h\left(\mathrm{~J} / \mathrm{s} / \mathrm{m}^{2} / \mathrm{K}\right)$ and the representative length $L(\mathrm{~m})$.

$$
\beta=h L / k
$$

Equation (13) can be obtained by substituting Eqs. (11)
Table 6. Mechanical and thermal properties of $\mathrm{MgO}-\mathrm{C}$ bricks.

\begin{tabular}{l|c|c|c}
\hline \multicolumn{1}{c|}{ Sample } & $\mathrm{MgO}-10 \% \mathrm{C}$ & $\mathrm{MgO}-15 \% \mathrm{C}$ & $\mathrm{MgO}-20 \% \mathrm{C}$ \\
\hline Thermal expansion coefficient $(1 / \mathrm{K})$ & $1.52 \times 10^{-5}$ & $1.09 \times 10^{-5}$ & $1.12 \times 10^{-5}$ \\
\hline Static elastic modulus $(\mathrm{MPa})$ & 1416 & 1108 & 1022 \\
\hline Poisson's ratio $(-)$ & 0.42 & 0.38 & 0.35 \\
\hline Thermal conductivity $(\mathrm{J} / \mathrm{s} / \mathrm{m} / \mathrm{K})$ & 26.4 & 34.3 & 53.3 \\
\hline Representative length $(\mathrm{m})$ & \multicolumn{3}{|c}{0.16} \\
\hline Heat transfer coefficient $\left(\mathrm{J} / \mathrm{s} / \mathrm{m}^{2} / \mathrm{K}\right)$ & 1538 \\
\hline Temperature drop, $\Delta \mathrm{T}(\mathrm{K})$ & 1300 \\
\hline
\end{tabular}

and (12), and Eq. (14) can be obtained by taking the logarithm of both sides of Eq. (13).

$$
\begin{aligned}
N_{t}= & \frac{2}{C^{\prime} \cdot Y^{n^{\prime}} \cdot \pi^{\frac{n^{\prime}}{2}} \cdot(n-2) \cdot a_{0}^{\frac{n^{\prime}-2}{2}}} \\
& \left\{\frac{1-v}{\alpha \cdot E \Delta T}\left(1.45+\frac{4.95}{\beta}\right)\right\}^{n^{\prime}} \exp \left(\frac{Q}{R T}\right)
\end{aligned}
$$

$$
\begin{aligned}
\log N_{t}= & n^{\prime} \cdot \log \left\{\frac{1-v}{\alpha \cdot E \Delta T}\left(1.45+\frac{4.95}{\beta}\right)\right\} \\
& +\log \left[\frac{2}{C^{\prime} \cdot Y^{n^{\prime}} \cdot \pi^{\frac{n^{\prime}}{2}} \cdot(n-2) \cdot a_{0}^{\frac{n^{\prime}-2}{2}}} \exp \left(\frac{Q}{R T}\right)\right]
\end{aligned}
$$

The numerical index $n^{\prime}$ could be calculated from Eq. (14) by substituting the experimental conditions and results, in the same way as in the fatigue failure test.

The numerical index $n^{\prime}$ was obtained by substituting the value of the cyclic heating number $N_{t}$ when large cracks or spalling were generated in the thermal spalling test, Poisson's ratio obtained in Table 4, the mechanical properties shown in Table $6{ }^{25,26)}$ and the experimental conditions into Eqs. (13) or (14). The heat transfer coefficient $h\left(\mathrm{~J} / \mathrm{s} / \mathrm{m}^{2} / \mathrm{K}\right)$ was applied to the value for heat transfer between a solid brick and water, and calculated from the experimental conditions of the thermal spalling test. The results are shown in Table 7 and Fig. 19. The numerical index $n^{\prime}$ which was obtained from the thermal spalling test decreased as the carbon content in the $\mathrm{MgO}-\mathrm{C}$ bricks decreased.

Furthermore, the numerical index $n$ which was obtained from the fatigue failure test was almost the same as the numerical index $n^{\prime}$ which was obtained from the thermal spalling test. Hence, the characteristic material constants obtained in the fatigue failure and thermal spalling tests were equivalent.

In the thermal spalling test, since thermal shock resistance improved when the numerical index $n^{\prime}$ increased, $\mathrm{MgO}-$ $20 \% \mathrm{C}$ brick, which has a comparatively high carbon content, was regarded as a relatively superior material for thermal spalling resistance. Moreover, the index $n$ that was obtained from the fatigue test increased with the carbon content in the brick and agreed with that obtained from the thermal spalling test. Therefore, it is estimated that a material which has a high value of $n$ has strong resistance to mechan- 
Table 7. Comparison of numerical index obtained from fatigue failure test and thermal spalling test.

\begin{tabular}{ccc}
\hline Sample & $n$ (fatigue failure test) & $n^{\prime}$ (thermal spalling test) \\
\hline MgO-10\%C & 29.8 & 29.3 \\
MgO-15\%C & 35.3 & 37.7 \\
MgO-20\%C & 52.4 & 47.9 \\
\hline
\end{tabular}

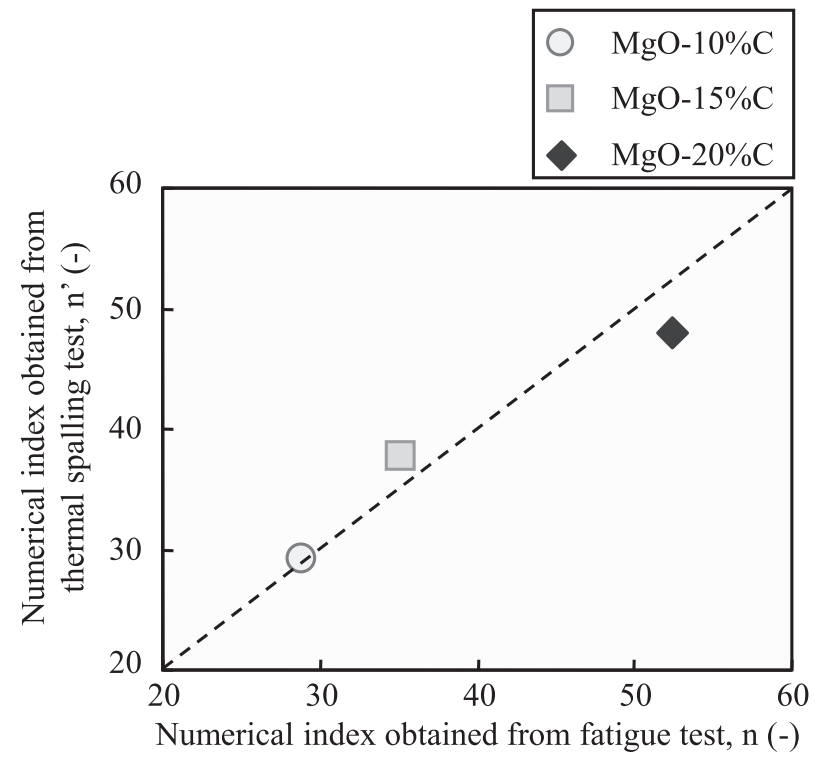

Fig. 19. Comparison of numerical indexes obtained from fatigue failure test and thermal spalling test.

ical fatigue fracture. (Details are discussed in the next paragraph.) Hence, it was found that a brick with strength against dynamic fatigue failure is also a reason for excellent resistance against thermal spalling. Based on this discussion, a relationship in which crack growth behavior in fatigue failure is equivalent to that of thermal spalling in $\mathrm{MgO}-\mathrm{C}$ brick was recognized.

\subsection{Consideration of Physical Implication of Numeri- cal Index $\boldsymbol{n}$ and Role of Carbon in Brick}

In these experimental results, the numerical index $n$ increased in both the thermal spalling test and fatigue test when the carbon content in $\mathrm{MgO}-\mathrm{C}$ brick increased. In this section, the meaning or implication of the index $n$ for fatigue life and fracture behavior is considered. The dynamic thermal fatigue fracture resistance coefficient, $R_{f}$, is expressed by Eq. (15) according to J. P. Singh et al. ${ }^{5}$

$$
R_{f}=\frac{K_{d}}{(n-2) C^{\prime}}\left[\frac{(1-v) k}{\alpha E}\right]^{n} \cdot \exp \left(\frac{Q}{R T}\right)
$$

where, $K_{d}$ is thermal diffusivity. This equation shows the strength of the material against dynamic thermal fatigue fracture. The resistance coefficient increases with index $n$. In a word, it can be regarded that the material which had a high value of $n$ had high resistance to dynamic thermal fatigue.

On the other hand, focusing on Eq. (2), the physical implication of the index $n$ can also be considered as the degree of sensitivity to changes in the growth of the crack and in the stress intensity factor. According to Eq. (2), the crack growth rate per unit loading cycle increased with the numerical index $n$. Therefore, it was thought that fatigue life will decrease when $n$ decreases. This paradox was considered as follows:

From the behavior of horizontal strain during cyclic stress loading shown in Figs. 11 and 12, it is presumed that cracks will begin to progress in the early stage of loading in the $\mathrm{MgO}-15 \% \mathrm{C}$ brick, which has a comparatively lower carbon content, because the amount of strain in the horizontal direction also increases in the early stage of loading repetition, whereas, in the $\mathrm{MgO}-20 \% \mathrm{C}$ brick, because the strain change rate was almost zero in the middle stage and the strain rate increased immediately just before fracture, it is presumed that the crack growth rate increases rapidly in the later stage of loading, including just before fracture. Namely, it is inferred that comparatively high carbon content bricks display characteristic behavior in which crack growth begins later (the number of repetitions before crack growth begins is larger), but the crack growth rate before fracture is higher. In contrast, in comparatively lower carbon content bricks, crack growth begins in an early stage of loading and the crack growth rate is slower than that in high carbon content bricks. As a result, the high value of $n$ obtained in the comparatively high carbon content brick was associated with a high fatigue life, and a low value of $n$ was obtained in the low carbon content brick. That is, it is supposed that the numerical index $n$ obtained from the fatigue test corresponded to the crack growth rate at a later stage of loading before fracture.

Next, the effect of carbon on fatigue fracture was considered. From the results of this review, it was found that the fatigue fracture behavior of the brick with a resin system binder did not display temperature dependence, but showed dependency on the carbon content. On the other hand, it is thought that the fatigue life of the refractory was related to the difference in the uniting force between large particles and the matrix, that is, the difference of bridging stress on the interface between the large particles and the matrix. ${ }^{27)}$ Observation revealed that cracks in refractories progressed in the matrix (i.e., small grain complex) along the edge of large particles. From these results, it was presumed that the carbon which is present in the matrix prevents crack progress, or that this carbon plays a role of resistance to crack growth. Therefore, it was inferred that $\mathrm{MgO}-20 \% \mathrm{C}$ had relatively higher fatigue life than $\mathrm{MgO}-15 \% \mathrm{C}$ and $\mathrm{MgO}-10 \% \mathrm{C}$ because the effect of carbon in impeding crack progress or in crack progress resistance increases with the carbon content in the refractories.

However, the above-mentioned consideration has not yet been demonstrated empirically and thus remains in the region of conjecture. Many points in connection with the fatigue failure behavior of refractories also remain to be elucidated, such as the fracture toughness of the refractory, crack growth behavior, activation energy for crack growth, fatigue failure behavior in other refractories, and so on. Hence, it is necessary to continue these investigations of iron- and steelmaking refractories. The fatigue fracture mechanism of carbon-content bricks also requires further examination in the future. 


\section{Summary}

The relationship between compressive stress and the number of repetitions of loading in $\mathrm{MgO}-\mathrm{C}$ bricks was investigated at room temperature, $1273 \mathrm{~K}$ and $1473 \mathrm{~K}$ to clarify the fatigue failure behavior of $\mathrm{MgO}-\mathrm{C}$ refractories under cyclical compressive loading. The relationship between fatigue failure and thermal spalling was also investigated by estimating the characteristic material constant $n$ in terms of fracture mechanics. The results are summarized as follows.

(1) It was found that the relationship between the ratio of compressive stress for compressive strength and the number of repetitions in $\mathrm{MgO}-\mathrm{C}$ was not affected by the temperature of the atmosphere, there being no difference between the fatigue failure behavior at room temperature and at high temperatures. When the numerical index $n$ was obtained and compared in this work from the results of a fracture mechanics discussion, no difference was seen in the value of $n$ at low and high temperatures in bricks with the same carbon contents. That is, $n$ was substantially the same under both temperature conditions, indicating that $n$ is independent of temperature.

(2) Fatigue fracture life under the same acting stress ratio decreased as the carbon content in the $\mathrm{MgO}-\mathrm{C}$ bricks decreased. In other words, $\mathrm{MgO}-\mathrm{C}$ bricks with higher carbon contents possess superior strength against dynamic fatigue failure. When the numerical index $n$ was obtained and compared in this work from the results of a fracture mechanics discussion, the value of $n$ was smaller in bricks with lower carbon contents.

(3) In the thermal spalling test, the number of heating cycles at which small cracks and large cracks were generated decreased as the carbon content in the bricks decreased.

(4) The ratio of the dynamic elastic modulus to the initial elastic modulus decreased gradually. In the thermal spalling test, as the number of heating cycles increased, the ratio of the dynamic elastic modulus to the initial elastic modulus decreased gradually. Furthermore, it was observed that, as the carbon content in the bricks decreased, the rate of decrease of the dynamic elastic modulus became larger.

(5) The numerical index $n$ which was obtained from the fatigue failure test was almost the same as the numerical index $n^{\prime}$ obtained from the thermal spalling test. Based on this, a relationship in which crack growth behavior in fatigue failure is equivalent to that in thermal spalling in $\mathrm{MgO}-\mathrm{C}$ brick was recognized, and it was found that a brick which has strength against dynamic fatigue failure is also one reason for excellent resistance against thermal spalling.

\section{REFERENCES}

1) W. D. Kingery, H. K. Bowen and D. R. Uhlmann: Introduction to Ceramics (2nd ed.), A Wiley-Intescience Publication (Jon Wiley and Sons Inc.), New York (London Sydney Toronto) (1961), 787.

2) Y. Hoshiyama, O. Nomura, H. Nishio and K. Ichikawa: Taikabutsu, 48 (1996), 1, 35

3) M. Kakihara, H. Tada and E. Iida: Taikabutsu, 61 (2009), 6, 285.

4) N. Kamiya and O. Kamigaito: J. Mater. Sci., 14 (1979), 573.

5) J. P. Singh, K. Nihara and D. P. H. Hasselman: J. Mater. Sci., 16 (1981), 2789.

6) H. N. Ko: J. Soc. Mater. Sci., Jpn., 39 (1990), 1385.

7) H. N. Ko: J. Soc. Mater. Sci., Jpn., 42 (1993), 481, 1207.

8) S. Yokokura: Yogyo-kyokai-shi, 93 (1985), 6, 322.

9) M. Sato, M. Fujimoto, Y. Sato and Y. Kakuta: Proc. of Hokkaido Chapter of the JSCE, JSCE, Hokkaido, 56 (A) (2000), V-49, 700.

10) M. Fujimoto, M. Sato, Y. Sato and Y. Kakuta: Proc. of Hokkaido Chapter of the JSCE, JSCE, Hokkaido, 56 (A) (2000), V-50, 704.

11) K. Matsumoto, Y. Sato, T. Ueda and L. Wang: J. Adv. Concr. Technol., 6 (2008), 2, 337.

12) T. Suruga, T. Hokii, K. Asano and K. Otsuka: Taikabutsu, 53 (2001), $8,461$.

13) Y. K. Malyshkin and I. P. Basyas: Trans. Indian Ceram. Soc., 44 (1985), 5, 112.

14) Y. Xaozang, K. Gotoh, T. Miki, Y. Kiyota, T. Takeuchi, H. Takeuchi, Y. Hino, A. Kasai, N. Sakaguchi, Y. Ohsugi, A. Wada, S. Nishizawa, K. Okita, T. Ueda, Y. Sato and K. Matsumoto: CAMP-ISIJ, 23 (2010), 891.

15) R. Furushima, Y. Matsuo, T. Shirota and K. Yasuda: J. Mater. Sci., 42 (2007), 8652

16) M. Ishikawa: Taikabutsu, 52 (2000), 12, 667

17) W. J. Lee and E. D. Case: J. Mater. Sci., 25 (1990), 5043.

18) W. J. Lee and E. D. Case: Mater. Sci. Eng., A154 (1992), 1.

19) T. Nishida and E. Yasuda: Ceramics-no-Rikigakutekitokusei (The Evaluation of Mechanical Property of Ceramics), Nikkankogyo-Shinbunsya, Tokyo, (1987), 205.

20) H. Okamura: Senkei-hakairikigakunyuumon (Introduction to Linear Fracture Mechanics), Baifukan, Tokyo, (1976), 133.

21) T. Fett, G. Martin, D. Munz and G. Thun: J. Mater. Sci., 26 (1991), 3320.

22) G. R. Irwin: Handbuch der Physik, Vol. 6, Springer Verlag, Berlin, (1958), 551.

23) D. P. H. Hasselman and W. A. Zdaniewski: J. Amer. Ceram. Soc., 61 (1978), 375.

24) J. C. Jaeger: Philos. Mag., 36 (1945), 418.

25) Okayama Ceramics Center Home Page: http://occ.optic.or.jp/

26) Refractories Handbook: Published by The Technical Association of Refractories, Tokyo, (1998), 523.

27) T. Akatsu: Private communication 